\title{
Environmental Monitoring System Based on Low-Cost Sensors
}

\author{
Behnam Mobaraki ${ }^{1}$, Seyedmilad Komarizadehası ${ }^{2}$, Francisco J. Castilla Pascual ${ }^{3}$
}

and José A. Lozano-Galant ${ }^{1}$

\author{
${ }^{1}$ Department of Civil and Building Engineering, Universidad de Castilla La Mancha. \\ Av. Camilo Jose Cela s/n, 13071, Ciudad Real, Spain. \\ behnam.mobaraki@uclm.es,Joseantonio.lozano@uclm.es \\ ${ }^{2}$ Department of Civil Engineering and Environmental Engineering, Universitat Politècnica de \\ Catalunya BarcelonaTech, C/ Jordi Girona 1-3, 08034, Barcelona, Spain \\ seyedmilad.komarizadehasl@upc.edu \\ ${ }^{3}$ Department of Civil Engineering,Universidad de Castilla La Mancha, Cuenca, Spain \\ fcojavier.castilla@uclm.es
}

\begin{abstract}
Temperature and humidity measurements provide useful information on multiple areas of civil engineering application such as Structural Health Monitoring (SHM), Structural System Identification (SSI) and structures rehabilitation. Majority of the existing commercial systems are so costly and also these measurement paradigms need many reference spots for a full-scale structure. The aforesaid paradigms are based on collecting data through smart devices, transferring information to each other and in the final stage processing the obtained information collaboratively through cloud computing or the others technologies. Taking into account the above information and obstacles, utilizing the Open Source Platforms (OSP) microcontrollers like Arduino as well as low cost sensors are attracting more and more attention. This paper gives a comprehensive information about the most determinant aspects of the aforementioned kits in terms of their pros and cons, installation procedure, communication protocol, number of the required connections and specific characteristics of the data acquisition system.
\end{abstract}

Keywords: Thermal Analysis, Low-Cost Sensors, Building Information Modeling, Open Source platforms, Structural Health Monitoring.

\section{Introduction}

Climate change has drastically affected crops, wildlife and people's livelihoods. One of the main elements that can prevent this tragedy is to lessen the energy consumption since this incident could also be caused by burning of the fossil fuels for the human needs. In this way, one of the most efficient solution is to control the waste of energy in the buildings and public places. The development of economically viable Building Information Modelling (BIM) using different software and hardware has become increasingly popular in recent years. An economic Arduino-based embedded system can be defined as combination of Arduino open source platform and low-cost environmental sensors. Studies of the Arduino-based as well as 
BIM-based controlling systems in different engineering fields were conducted by many scholars.

Barroca et al., (2013) have designed and Arduino-based controlling system for concrete structures. They have prepared thermal and temperature sensors inside the concrete in order to measure temperature and humidity of the concrete at different levels. Different low-cost particle sensors were assessed by calibration methods adapted from the US EPA 2013 Air Sensor Workshop recommendations. The six different elements of the examinations were linearity response, precision of measurements, limit of detection, dependence on particle composition, dependence on particle size, relative humidity and temperature influences (Wang et al., 2015). Bamodu et al., (2017) have used various types of humidity and temperature low cost sensors such as LM35 and DHT11 in order to control the indoor environment parameters of the buildings, heating, Ventilation, Air-Conditioning (HVACs).

Monitoring ventilation as well as thermal/humidity comfort level of the public places are vital issues since variation of the mentioned parameters might occur in different spaces. For instance, these variations may affect energy consumption and health of passengers in the subway. Marzouk and Abdelaty (2014) stablished Wireless Sensor Network (WSN) and BIMbased model in order to be able to monitor thermal condition in the different places of a subway. Kim et al. (2015) presented the development of Modelica Llibrry for BIM-based building energy simulation using an Object-Oriented Physical Modeling (OOPM) approach and Modelica, an equation-based OOPM language. Using the ModelicaBIM library they have

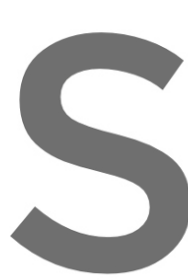
prepared system interfect automatic translation Foguem (2019) present dealing with the energy as heating, ventilating performance of prefalorica
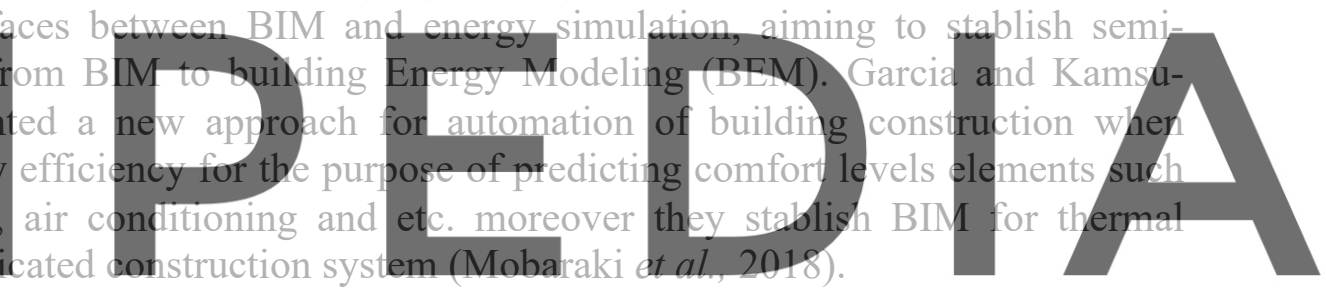

As is evident from the aforementioned studies, the advantage of using the low-cost sensors

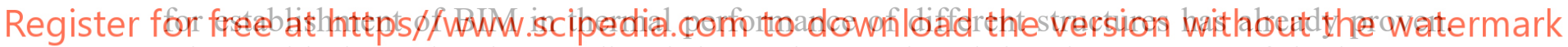
Along with the undertaken studies, it has to be mentioned that the accuracy of the low-cost sensors is a decisive parameter in reliability of the BIM. Therefore, in the section 2 of this article, a comprehensive information about the Arduino mechanism, types of smart connections and types of low-cost sensors will be presented. In the third section a detail explanation related to the performed experiments in terms of performance of low-cost sensors DHT22 will be explained.

\section{Arduino Sensors}

Arduino UNO is an open source software/hardware for making interactive electronic objects. The physical programable part is of $6.8 \mathrm{~cm} * 5.3 \mathrm{~cm}$ board which has 14 digital input/output pins, 6 analog inputs, 5 power pins (VIN, $5 \mathrm{~V}, 3.3 \mathrm{~V}$ and GND) with different performances, a $16 \mathrm{MHz}$ crystal oscillator, a USB connection for compiling the data as well as using power supplied form the laptop/computer, a DC power jack $(7-12 \mathrm{~V})$, a reset button for restarting the program/Arduino from the beginning and some small parts (Garin et al., 2018). For talking to the sensors through Arduino as well as programing the board through compiling the sketches the open- source Arduino Integrated Development Environment (IDE) software has 
been presented (Philips, 2019). This cross-platform application has written in Java, C and $\mathrm{C}^{++}$ and is compatible with all Windows, MacOS and Linux. The Arduino environment is extendable by utilizing the libraries. These libraries have written in $\mathrm{C} / \mathrm{C}^{++}$and they increase functionality of the sketches for working with hardware as well as manipulating data. One of the main capabilities of microcontroller is to read sensors and capture the values. In other words, it can be express that sensors are sort of objects, capable of converting physical quantity (like temperature or humidity) into an electrical quantity. For measuring different parameters through Arduino various types of sensors exist. For instance, temperature, motion, humidity, vibration, displacement, pressure and etc. these measurements might be done for several purposes such as smartening systems of metering, retail, logistic, agriculture and security. For the connection of a sensor to the Arduino and observing the measured parameters, sensor's library which defines a canonical set of predefined sensors and control ability, should be used. The Arduino's sensors are categorized as digitals and analogs. Analog sensors observe the external changes such as temperature and humidity variations and yield analog voltage that represents the measured parameter. For instance, 2V might mean 23 degrees Fahrenheit. Normally this output voltage is between 0 to $5 \mathrm{~V}$. Analog signals might be influenced by the ambient noise which leads to produce errors in the output signals. However, the digital sensors generate discrete values like 0 and 1 which are so called digital/binary signals. They have lower range of calculation than the analog ones. Therefore, the analog sensors are more appropriate for wide range of measurements. As far as the analog outputs are

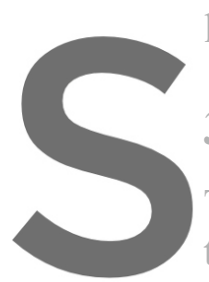
liable to change rapidly and unpredictably, digital sensors are preferred over the analog ones. 3 Arduino-Based Thermal Controlling System Temperature and humidity are one of the decisive factors mea to evaluate the accuracy of the low-cost temperature sensor
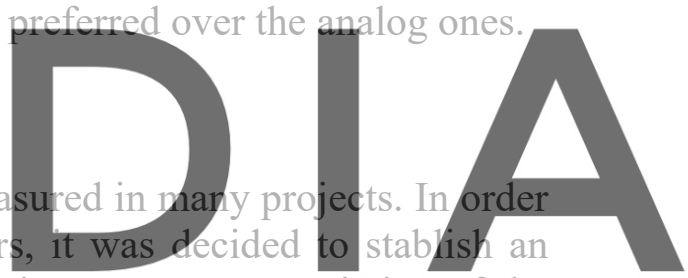

Arduino-based thermal controlling system. This system is going to measure variation of the 


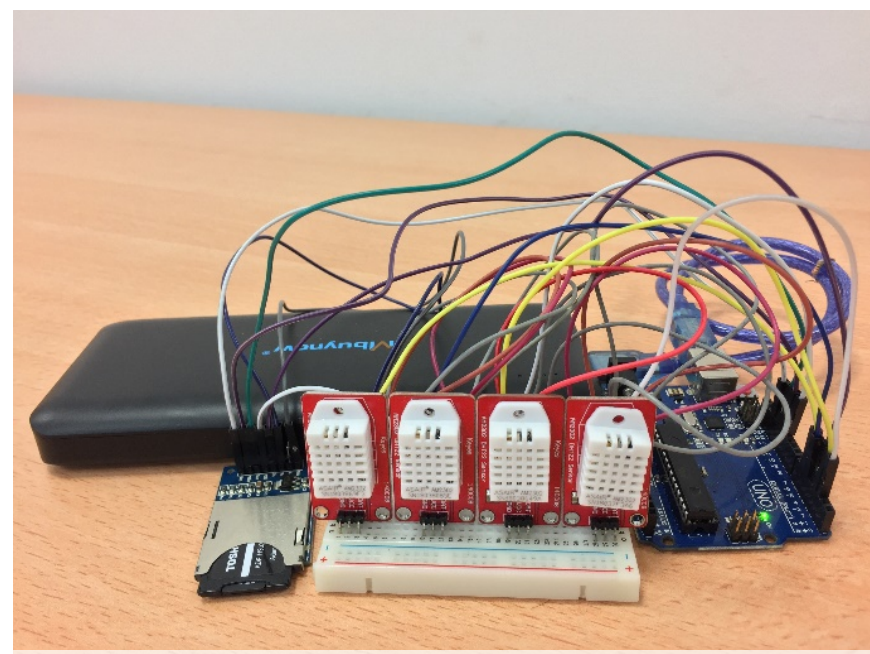

Figure 1. The Arduino-based thermal measurement system.

\subsection{Hardware Description}

Fig.2 shows all the used particles for establishment of this measurement system Arduino UNO, DHT22 sensor, breadboard and SD Card/Reader. The proposed system is based on the

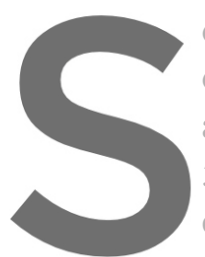
open source Arduino UNO platform and low-cost temperatufe/humidi operating temperature o also capable of measuring humidity from

$5 \%$ RH. DHT22 sensor cost humidity and temperature communication system sensors in the
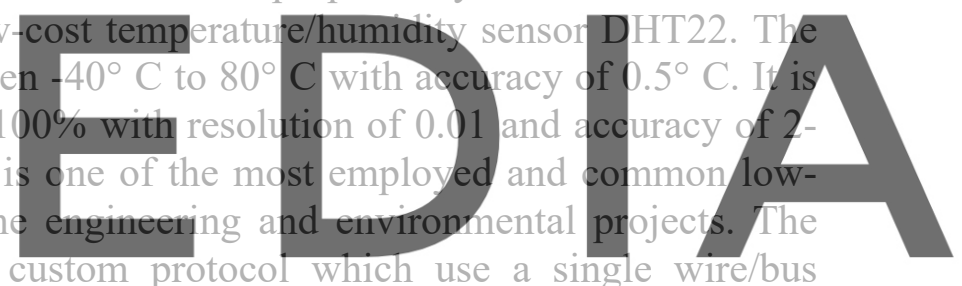

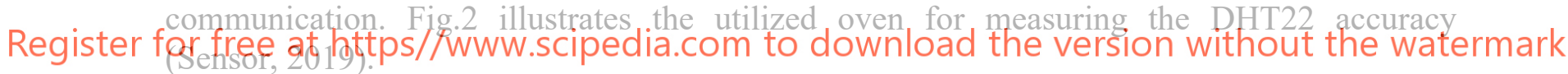

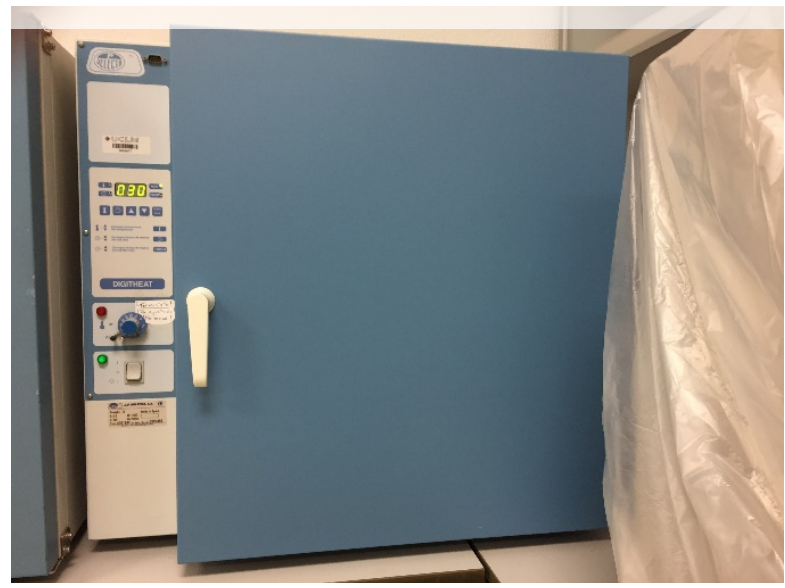

Figure 2. The utilized oven SELECTA-2001244 for the experiment. 


\subsection{Comparative Sensors Result}

To estimate the responses of DHT22 sensor as well as their precision, variation of the temperature versus time related to the 4 sensors shown in the Fig.3. The sensors adjusted to record the temperature with frequency of 2 seconds. All of them have been registered to measure the temperature inside an oven in the laboratory of Universidad de Castilla-La Mancha (UCLM). Model of the oven is SELECTA-2001244, Capable of changing temperature from $10^{\circ} \mathrm{C}$ to $250^{\circ} \mathrm{C}$ with precision of $2 \%$ and resolution of $1^{\circ} \mathrm{C}$. In order to figure out the precision of the sensors, the oven adjusted to reach to the temperature of $30^{\circ} \mathrm{C}$ and keep working for period of time. As shown in the Fig.3, variation of the temperature has been divided to two parts. The first part shows variation of the temperature for reaching to the adjusted temperature and the second part depicts behavior of the sensors at the fixed temperature of $30^{\circ} \mathrm{C}$. In the second part the sensor number 1 , number 2, number 3 and number 4 are showing constantly the temperature of $29.6^{\circ} \mathrm{C}, 29.4^{\circ} \mathrm{C}, 29.4^{\circ} \mathrm{C}$ and $29.6^{\circ} \mathrm{C}$ respectively. These observations indicate the discrepancy between the low-cost sensor DHT22 for recording the homogenous temperature in the oven. It has to be mentioned that in our measurements not only we are facing with error of the sensors, but also the oven has its own range of error, $2 \%$, as mentioned in the above.
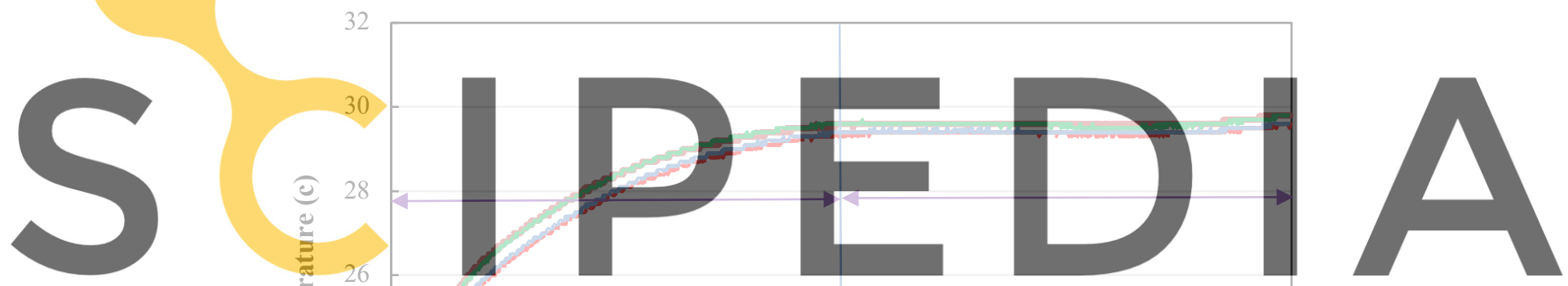

Register for free a hattps//www.scipedia.com to download the version without the watermark

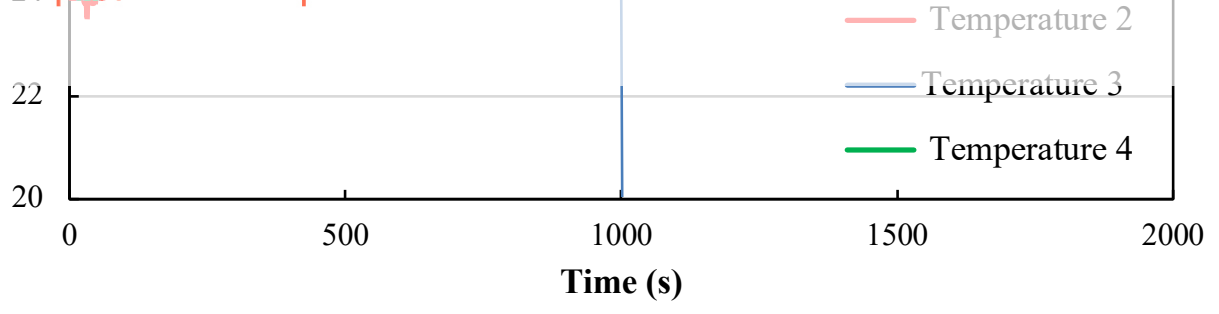

Figure. 3. Variation of the temperature related to the four DHT22 sensors.

By this graph it is clearly visible that the accuracy tolerance of the temperature sensor DHT22 is around $0.5^{\circ} \mathrm{C}$. The obtained range of accuracy is almost as equal as the one indicated by the manufacturer in the DHT22 datasheet, $0.5^{\circ} \mathrm{C}$ (Zarnik and Papa, 2019). Low cost environmental sensors are so useful for determining the thermal parameters of buildings (Mobaraki and vaghefi, 2018). Moreover, they are applicable for determining characteristic of structures and inferring variation humidity and temperature of concrete during the construction procedure (Mobaraki et al., 2020). 
In order to have better recognition of the sensors' accuracy it is better to have a statistic view on the obtained results. In statistic standard deviation is defined as amount of dispersion of a data set. In this criterion, a low range of standard deviation shows that the values are tending to get close to the average/mean of the dataset however, the high range of that demonstrate that the set of data are dispersed and has a wider range. It can be seen from Fig. 4 that the derived standard deviation related to the four sensors vary from 0.04 to 0.13 which shows a good performance trend. These 1000 measured point are belong to the second part of the measurement when the homogenous temperature of $30^{\circ} \mathrm{C}$ starts in the oven.

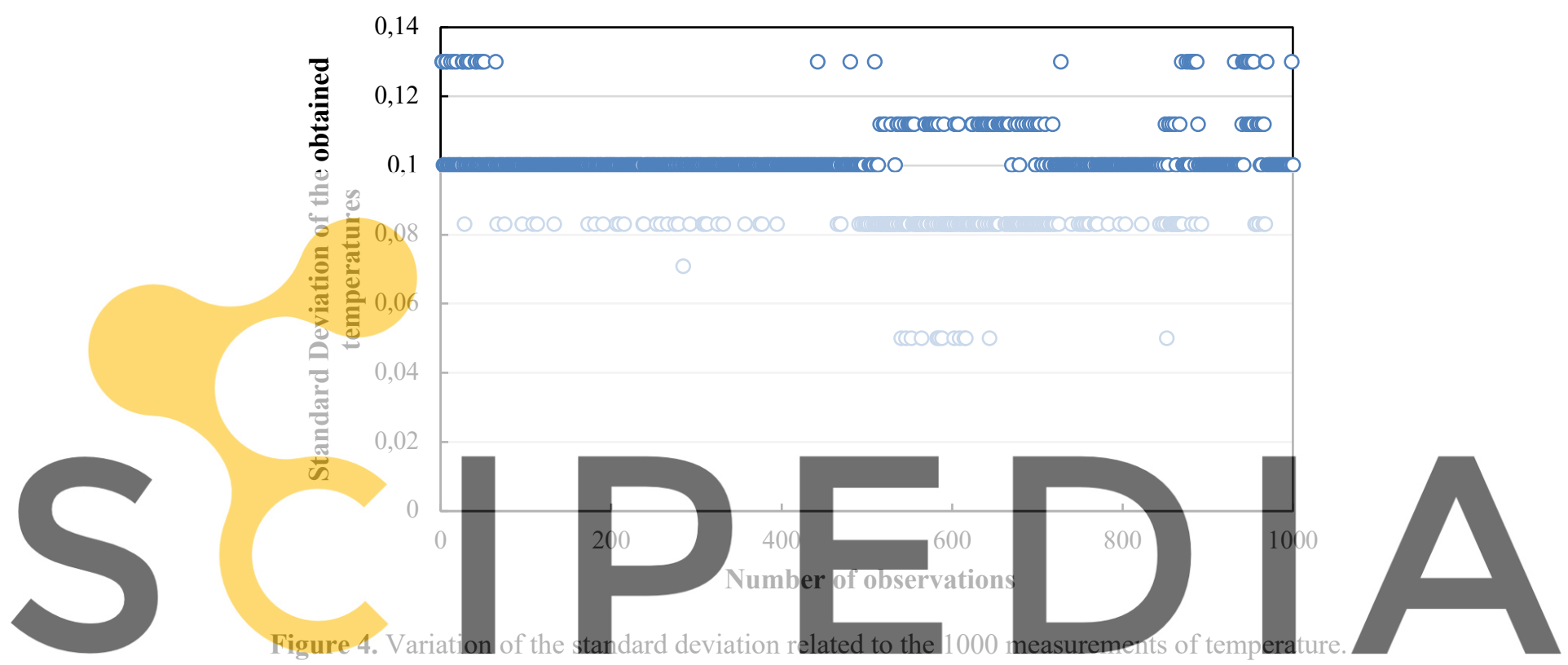

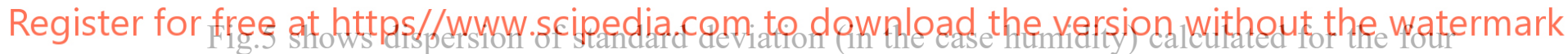
sensors by 1000 measurements at the third step of Fig. 5. Standard deviation is always positive number. Majority of the observations were extended above 1.25 close to 1.3 $(1.25 \leq$ Standard deviation $\leq 1.3)$. A low range of standard deviation same as Fig.4 (related to temperature) shows that the observations tend to be close to the average temperature, however the higher one presents (Fig. 7) the wider range of observations discrepancy (Mobaraki and Vaghefi, 2016). 


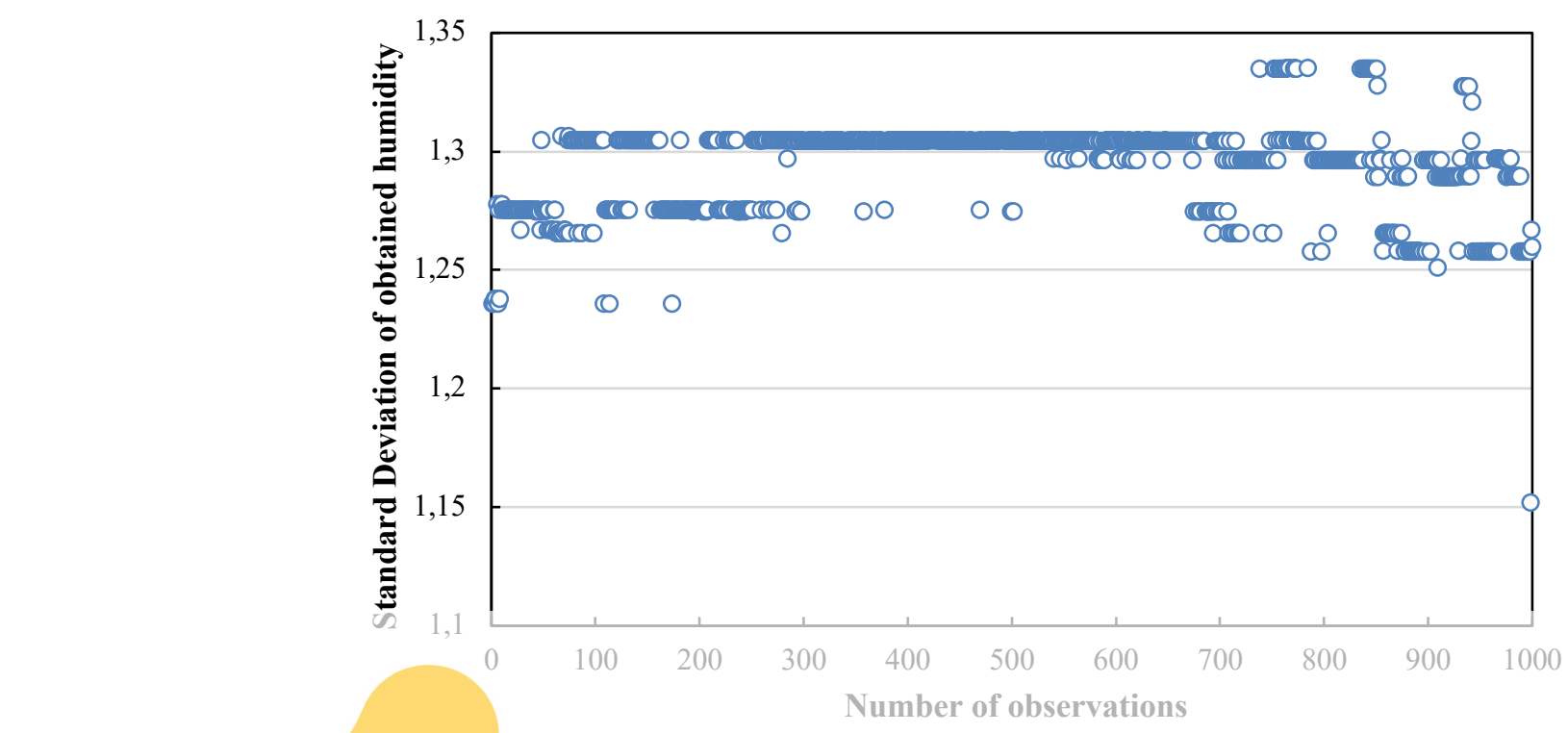

Figure 5. Variation of the standard deviation related to the 1000 measurements of humidity.

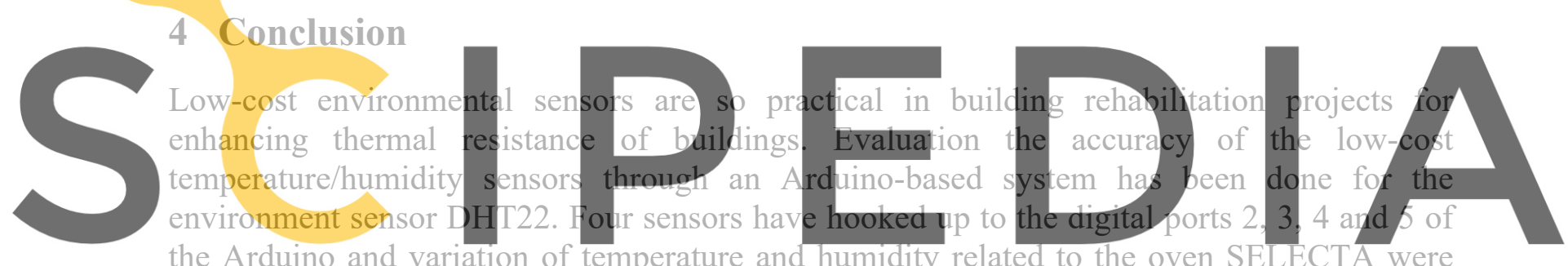

the Arduino and variation of temperature and humidity related to the oven SELECTA were

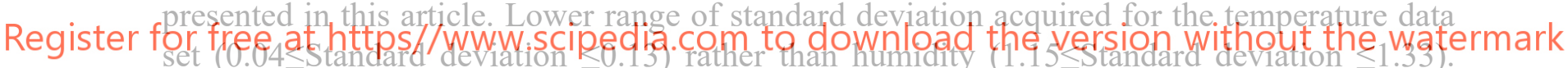

Which means that the sensor DHT22 is more accurate in terms of measuring temperature

rather than humidity. From the obtained results it is clearly visible that the range of accuracy or in the other word the precision of the temperature sensor DHT22 is around $0.5^{\circ} \mathrm{C}$ which is almost equal to the one mentioned in the DHT22 datasheet, $0.5^{\circ} \mathrm{C}$.

\section{Acknowledgements}

The authors are indebted to the Spanish Ministry of Economy and Competitiveness for the funding provided through the research projects BIA2013-47290-R, BIA2017-86811-C2-1-R, and BIA2017-86811-C2-2-R founded with FEDER funds It is also to be noted that funding for this research has been provided to $\mathrm{Mr}$. BEHNAM MOBARAKI by the Spanish Ministry of Economy and Competitiveness through its program for his $\mathrm{Ph} . \mathrm{D}$. It is also to be noted that part of this work was done through grant number 2018-COB-9092 from Universidad de Castilla La Mancha (UCLM).

\section{ORCID}

Behnam Mobaraki: https://orcid.org/0000-0002-2924-643X

Seyedmilad Komarizadehasl: https://orcid.org/0000-0002-9010-2611

Francisco Javier Castilla Pascual: https://orcid.org/0000-0003-1961-6174

Jose Antonio Lozano-Galant: http://orcid.org/0000-0003-0741-0566 


\section{References}

Bamodu, O. Xia, L. and Tang L. (2017). An indoor invironment monitoring system using low-cost sensor network. Procedia. 606-666.

Barroca, N. Borges, L.M., Velez, F.J., Monteiro, F., Gorski, M. and Gomez, C.J. (2013). Wireless sensor networks for temperature and humidity monitoring within concrete structures. Construction and Building Material. 1156-1166.

Garin, A.M. Millan-Garcia. J.A., Bariri. A., Millan-Medel J. and Lizzaraga J.M. (2018). Environmental monitoring system based on an open source platform and the internet of things for a building energy retrofit. Automation in Construction. 201-214.

Garcia, L.G. and Kamsu-Foguem, B. (2019). BIM-oriented data mining for termal performance of prefabricated buildings, Ecological Informatics. 61-72.

kim, J.B. Jeong, W. Clayton, M.J. Habrel, J.S. and Yan, W. (2015). Developing a physical BIM library for building termal energy simulation. Automation in construction. 16-28.

Marzouk, M. and Abdelaty, A. (2014). Monitoring termal confort in subways using building information modeling. Energy and Buildings. 252-257.

Mobaraki, B. Komarizadehasl S. Castilla-Pascual F.J. and Lozano-Galant, J.A. (2020). Application of low-cost sensors for accurate indoor environmental monitoring. J. Automation in Construction.

Mobaraki. B. and Vaghefi. M. (2018). Investigation of dynamic behavior of concrete bridge columns under surface blasting, Sharif Journal of Civil Engineering. 133-141.

Mobaraki. B. and Vaghefi. M. (2015). Numerical study of the Depth and cross-sectional shape of tunnel under Surface explosión, Tunnelling and underground space technology. 114-122.

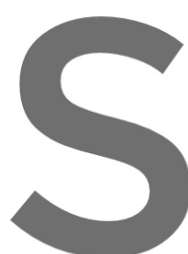

Mobaraki. B. and Vaghef. detonation. Combustio

Philips Semiconductors,

The Sensor Company, (2019

Wang, Y., Li, J., Jiang, three low-cost particl
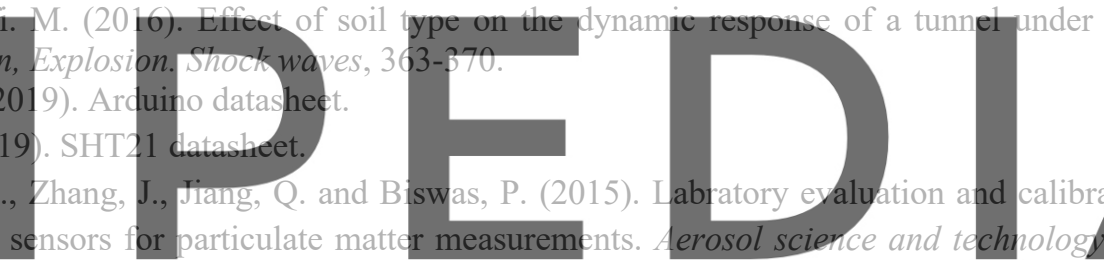
1077.

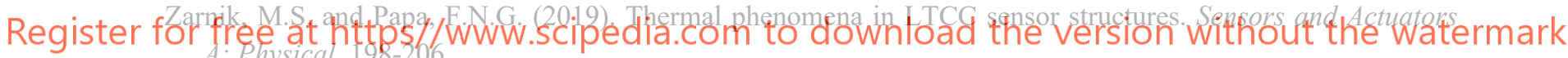

